How to Cite

Mantra, I. B. N., Astawa, I. N., \& Handayani, N. D. (2019). Usability of innovative learning models in higher

education. International Journal of Social Sciences, 2(1), 38-43. https://doi.org/10.31295/ijss.v2n1.91

\title{
Usability of Innovative Learning Models in Higher Education
}

\author{
Ida Bagus Nyoman Mantra \\ Universitas Mahasaraswati Denpasar, Indonesia \\ Corresponding author email: bagusmantra@unmas.ac.id \\ I Nengah Astawa \\ Universitas Mahasaraswati Denpasar, Indonesia \\ Email: nengah_astawa@yahoo.com \\ Nengah Dwi Handayani \\ Universitas Mahasaraswati Denpasar, Indonesia \\ Email: ndwihandayani@gmail.com
}

\begin{abstract}
The present study was conducted to analyze the teaching models employed by English language lecturers in higher education. The analysis includes the selected teachings models and their implementation in real classroom settings. This study made use of a qualitative research design in which the data were analyzed utilizing deep argumentation and the analysis was presented descriptively. The required data were collected through direct observation and in-depth interviews with the selected English language lecturers. The collected data were analyzed in a comprehensive analytical manner to obtain the findings. The findings of the present study indicated that English language lecturers employed various models of teaching. The selected teaching models are based on currently developed language approaches. The classroom observation indicated that the teaching models are sufficiently effective in improving students' competence. The study implies that English language lectures should maintain the use of appropriate teaching models to enhance their students' competence.
\end{abstract}

Keywords---education, innovative, learning models, usability.

\section{Introduction}

Language is a medium of verbal communication among the human community throughout the world. Through the medium of human language, people communicate and share a wide range of meanings, ideas, emotions, feelings and a variety of problems in life. Therefore, there is no question and doubt that language plays a very vital role in the existence and meaning of human life. To increase the intensity and quality of relationships, communication, interaction, business transactions, trade and diplomacy with the nations of the world, English has been selected and designated as a compulsory language to be taught in schools from junior high schools to university. The choices and decisions are very logical, strategic and prospective because English is a lingua franca of international speakers at and has spread across the globe (Akbari et al., 2010).

The progress and developments of telecommunication systems, which are very advanced, has made English an even more important medium of communication. Bilingual and International schools have emerged, making English the language of instruction in the teaching and learning process. It can be an indicator of the importance or urgency of English mastery in Indonesia. If people are committed to being competitive in the global market, especially in increasingly competitive areas, such as the labor market, the mastery of foreign languages, especially English, according to the researcher, is an obligatory thing. Therefore in order students are equipped with adequate English, proper teaching and assessment are needed (Widiastuti, 2018; Widiastuti, \& Saukah, 2017).

The development of global life is marked by the continual and rapid growth of science and technology, as well as changes of the socio-cultural constellation. The parents, who have the financial ability, tend to send their children to

ISSN 2632-9409

Received Jan 18, 2019 / Accepted Jun 18, 2019 / Published Jul 31, 2019 
international standard schools. They believe that global competition demands labors that are not only having advanced technical ability and excellent life skills, but also mastery of communicative English. The nations can only compete in the globalization era and its existence will be recognized and considered by other nations if the mastery of the English language by its people has been intensified (Widiastuti, 2017).

Labor recruitment in the globalization era has always made the mastery of written and spoken English as one of the most important requirements. To address the importance of mastering English for work purposes and to improve the quality of human resources in Indonesia, in the education sector today English has been incorporated into the curriculum and is a compulsory subject in schools and all higher education institutions. Learning English is easy when the learning activities are presented interestingly. Sometimes there are still many students who find learning English is difficult. This is due to various reasons. Some students assume that English is hard to understand and to communicate (Astawa et al., 2017).

There are still many problems we face in the world of education at present and increasingly complex so there needs to be a contribution of ideas that is suitable to overcome these problems. As educators, we should not stay effortless in facing these problems. Therefore, we can overcome the problem through better ways of teaching. As an educator in carrying out the learning and teaching process, we should always focus on how to convey the material to students comprehensively so that students understand (Salam et al., 2019). In achieving the results of the learning process there is a need for innovation at all times so that students continue to think about what strategies should learners do in different conditions and situations (Hadjerrouit, 2015). This is because every different situation and condition will require different handling strategy. When applied to the same strategy, the learning and teaching process is ineffective and inefficient. Here learners need a continuous thought to make innovations in each process of learning and teaching. So that it can be said that innovative learning is needed in the teaching and learning process (Killian \& Bastas, 2015). In this case, students have to learn cooperatively to enhance their competence and develop continually their social skill (Yusuf et al., 2019).

The current curriculum of English language teaching aims at improving students' English skills related to the field of science and also to improve communicative competence. English subjects are often a tedious and frightening specter for most students and students. Such conditions should be able to stimulate and challenge language educators to better design learning and implement it conductively. The learning process should be conducted based on communicative approaches. In this case, every language learning activity must be designed in such a way to meet the new views about the principles underlying the approach to learning English. This is important to make the learning activities meaningful for the students (Astawa et al., 2017).

An understanding of work principles that underlies the communicative approach and a comprehensive understanding of communicative competence as a concept, therefore a new learning paradigm as a product of innovation provides more processes to restore the nature of students as human beings who have all the potential to experience the process of developing humanity. Learning paradigms that can disturb students' hearts to awaken their mode should be the first focus in developing learning facilities (Hsieh et al., 2011). Learning is called effective if it can facilitate students to achieve specified learning goals (Kumaravadivelu, 2006b). For this reason, the lecturer needs to develop a strategy that is by the characteristics of students and able to make it reach the competencies specified in the learning objectives (Keefe, 1987). Development of instructional strategies that can be done by instructors to create learning situations that support the achievement of predetermined competencies Moussa-Inaty $e t$ al., (2019), so that innovative learning is very effective for the learning and teaching process.

It can be said that without effective innovative learning, the learning process is not going to be successful. Therefore lecturers of English should carefully consider the most effective learning model to be implemented in their classrooms. Innovative learning is considered to be important to be carried out in the class due to some problem in learning especially in learning motivation. Lack of student motivation is believed to be one of the main problems in learning English. This may be due to students' perceptions of English. Because of the nature of the language which is hardly found in Indonesian, many of them consider it a difficult lesson to learn. As a result, they miss class, and when they attend class, it is not because they want to learn English, but maybe because they are afraid of failure.

The phenomenon of English language instruction in higher education is varied due to lecturers' competence in conducting the learning process. Therefore intensive study on how learning models being carried out by the lecturers are very important to reveal the real existing practices in the classroom. This study aims at investigating the learning models currently implemented by the lecturers to gain a better understanding and the findings can be used as guidance for improvement of learning. 


\section{Materials and Methods}

This study made use of a qualitative research design. A qualitative research design differs from a quantitative research design in which the procedures usually don't provide the researcher with a step by step plan or fix procedures to follow. In quantitative research, the design determines the researcher choice and action, however, in qualitative research, the researchers' choices and action determine the design. Qualitative research proves explanation to extend our understanding of our phenomena, or promote the opportunity of informed decision for social action. Qualitative research furthermore contributes to theory, educational practice, policymaking, and social consciousness. The purpose of qualitative research is to carry out a basic interpretive study to understand how people make sense of their lives and their experiences. Therefore, it can be stated that the qualitative study is the study which was conducted in a natural, rather than experimental, and setting. Qualitative research is the main concern to understand the social problem or phenomena which are being studied.

The subject of this study is a source where information about an object is obtained. Since the present study is about analyzing the implementation of English language programs in English Education Study Program, the subjects are the English lecturers as research participants. The data were collected by doing classroom observations and indepth interviews with the English lecturers. The participants of the study were chosen by doing random sampling technique to get various data regarding the teaching models. The data were collected by conducting in-depth interviews, in relax situation to the lecturers to get data related to the teaching practices. The interview guide was the instrument used to collect data related to lecturers' teaching models. The data were also collected by doing direct observation. In this study, researchers conducted observations on assessment activities during the teaching and learning process in the classroom. Observations were conducted to find out the implementation of teaching strategies conducted by lecturers in the classroom. The data obtained from interviews were firstly transcribed and then interpreted. The transcription of the interview and observation were coded into categories. Then the categorized data were analyzed and described argumentatively.

\section{Results and Discussions}

Innovative learning is learning that is more student-centered. That is, learning that provides more opportunities for students to construct knowledge independently. Innovative learning bases itself on a constructivist paradigm. Innovative learning is usually based on a constructivist paradigm helping students to internalize, reshape, or transform new information. Transformation occurs through the creation of new understandings which is the result of the emergence of new cognitive structures. Deep understanding occurs when the presence of new information encourages the emergence or increase of cognitive structures that allow students to rethink their previous ideas. In constructive class settings, students are responsible for their learning, become autonomous thinkers, develop integrated concepts, develop challenging questions, and find answers.

Constructivist teaching settings that encourage active knowledge construction have several characteristics: (1) provide opportunities for students to learn from the set goals and develop ideas more broadly; (2) supporting the independence of students learning and discussing, making relationships, reformulating ideas, and drawing conclusions themselves; (3) sharing with students the importance of the message that the world is a complex place where there are multiple views and truth is often the result of interpretation; (4) placing student-centered learning and assessment that is able to reflect students' divergent thinking. Based on the interviews and classroom observation, it found that several classroom teaching models are mostly employed by English lectures such as direct learning, cooperative learning, problem-based instruction, and classroom discussion.

\section{Direct Instruction}

Direct Instruction is a learning model that emphasizes mastery of concepts by prioritizing a deductive approach. In this case, the lecturer acts as the conveyor of information, and in this case, the lecturer should use a variety of appropriate media. Information conveyed can be in the form of procedural knowledge (i.e. knowledge of how to do something) or declarative knowledge, (knowledge of something can be facts, concepts, principles, or generalizations). In direct instruction, the lectures focus to help students gain procedural knowledge, declarative knowledge, and develop learning skills. Theoretically, direct instruction focuses on the principles of behavioral psychology and social learning theory. The direct instruction model is specifically designed to develop student learning about procedural knowledge and declarative knowledge that is well structured and can be learned in stages. 
In the direct learning model, there are five very important phases. The lecturer begins the lesson by explaining the purpose and background of learning, as well as preparing students to receive the lecturer's explanation.

In direct instruction, the learning activity starts from the motivation phase is then followed by the presentation of teaching material or demonstration about certain skills. The lesson also includes providing opportunities for students to conduct training and provide feedback on student success. In the training and giving feedback phase, lecturers need to always try to provide opportunities for students to apply the knowledge or skills learned into real-life situations. To be successful, direct instruction requires very careful planning and implementation. Moreover, in order the learning activity becomes effective, direct learning requires detail skill or learning content carefully defined and the demonstration and the learning schedule is appropriately planned and carried out carefully.

It was found that although learning objectives can be planned jointly by lecturers and students, this model is primarily lecturer-centered. The management system of learning carried out by the lecturer must ensure the involvement of students, especially through attention, listening and recitation (question and answer) planned. This does not mean that learning is authoritarian, and without humor. This means that the environment is task-oriented and gives high expectations so that students achieve good learning outcomes. Therefore, properly planned and carefully designed learning materials certainly help the attainment of learning goals and successful implementation of direct instruction.

Based on the observation, direct instruction was often used by the lecturers and it was found to be an effective learning model to help students to be more independent in learning. Students then can maximize their capacity in developing their competence to achieve a higher level of comprehension of the learning materials. It was also claimed by the lecturers to be an encouraging learning model to be implemented in a higher level of English instruction.

\section{Cooperative Learning}

Cooperative learning is a teaching and learning strategy that emphasizes shared attitudes or behaviors in working or helping among others in the structure of regular cooperation in groups, consisting of two or more people. Cooperative learning is one form of learning based on constructivist understanding. Cooperative learning is a learning strategy with several students as members of small groups with different levels of ability. In completing their group assignments, each student group member must work together and help each other to understand the subject matter. In cooperative learning, learning is said to be unfinished if one of the friends in the group has not mastered the lesson material.

Based on the classroom observation, lecturers of English predominantly made use of cooperative learning because it is considered to be very effective to help students develop their social skill. Nowadays to have good social skill is very important because life is becoming more complex to face individually. Cooperative learning models are very different from direct learning. Cooperative learning model can be used to teach rather complex material, and more importantly, can help students and lecturers achieve learning goals with social dimensions and human relations. Cooperative learning goals are grouped into three parts, namely academic learning outcomes, acceptance of diversity, and development of social skills. Theoretically, cooperative learning is developed based on constructivist cognitive learning theory and social learning theory. These three dimensions of learning used as the fundamental concepts of the cooperative learning implementation in the classroom.

In the teaching-learning process, lectures divided the implementation of cooperative learning into six main phases. The lesson begins with the lecturer delivering the lesson objectives and motivating students to learn. This phase is followed by the presentation of information; often with reading material rather than verbally. Next students are grouped into learning teams. This stage is followed by lecturer guidance as students work together to complete their joint assignments. The final phase of cooperative learning includes presenting the final results of group work or evaluating what they have learned and rewarding group and individual efforts.

Most of the lecturers considered cooperative learning as a democratic process because students have an active role in determining what must be learned and how to learn it. The lecturer applies a high-level structure in group formation and defines all procedures, but students are given the freedom to control from time to time in the group. To succeed in implementing cooperative learning, comprehensively complete learning materials must be available and students have free access to the learning materials. Moreover, students should be strictly monitored to ensure they are learning seriously in groups. However, the classroom observation indicated that lecturers paid occasional attention to students' group work and more focused on gaining the results of students' group assignment. 


\section{Problem-Based Learning}

Problem Based Learning is not designed to help lecturers provide as much information as possible to students. The problem-based learning model is primarily developed to help students develop thinking skills, problem-solving, and intellectual skills; learn various roles of adults through their involvement in real or simulated experiences, and become autonomous and independent learners. The purpose of problem-based learning is to enhance students' thinking skills and problem-solving skills; adult modeling; and students who are autonomous and independent. The contemporary approach to problem-based learning rests on cognitive psychology and the constructivist paradigm of learning.

Based on classroom observation, English lecturers divided the process of problem-based learning into five main phases that begin with the lecturer introducing students to a problem and ending with the presentation and analysis of student work results. If the problem range is moderate, the five stages may be completed in several learning sessions, especially if the problem is very complicated to solve. Therefore, more time should be allocated to solve the problem and group discussion to attain appropriate results. Problem-based learning is characterized as an open and democratic process of learning, and students have a very active role in learning. In reality, the whole process helps autonomous students who believe in their intellectual skills require active involvement in an intellectually safe inquiry-oriented environment. Although lecturers and students carry out structured and predictable learning stages, the learning atmosphere is full of students' freedom in learning and full of challenging activities.

The classroom observation showed that lecturers tried to provide students with interesting and challenging problems to be solved by the lecturers. The students were divided into several groups and they were encouraged to work seriously in their groups. Classroom discussion was conducted at the end of the group discussion. All students were assigned to ask questions and gave solutions to the problems being discussed. The students were found to be active in participating in the classroom discussion and tried hard to solve the problems.

\section{Classroom Discussion}

Classroom discussion is mostly used by the English lecturers in teaching as it enables students to develop their social skill and learn to solve their problems with other students. Classroom discussion may occur in cooperative learning, between lecturers and several students on problem-based solving. Discussion is communication where audiences talk to others, share ideas and opinions with each other. Discussions are used by the lecturer to achieve the several learning objectives such as improving student thinking skill and helps them develop an understanding of academic material; encourage student involvement and participation by giving students a broad opportunity to express their ideas, and motivate students to get involved in class conversations; and help students learn communication skills and thought processes.

Furthermore, lecturers usually employ five stages in classroom discussion, starting with the lecturer delivering the learning topic and generating motivation; focus discussion; hold discussions; end the discussion, and summarize the discussion. One aspect of the discussion is the ability to improve cognitive growth, connect and unite cognitive and social aspects of learning. Lecturers believed that class discussion can be used to improve a positive social environment in the classroom. Considering the benefits of classroom discussion implementation, therefore many lecturers use this learning model more intensively compared to other learning models. Lecturers also found that classroom discussion helps students to improve their communicative skills and continually develop their critical thinking skill.

\section{Conclusion}

Through Innovative learning, lecturers can explore and develop students' competence and improve their students' critical thinking skill. Higher thinking skill is needed to continually enhance in order students can face the unpredictable changes of life nowadays. This study found that higher education educators still dominantly use direct instruction and classroom discussion in teaching; more innovative teaching models are utilized occasionally. This is because most of the lecturers believe that direct instruction is a quicker way to deliver their learning material to the students. Students, however, found direct instruction is not as interesting as more innovative teaching models. Therefore, lecturers are suggested to make use of more innovative teaching models when delivering the learning materials to the students to maintain students' learning motivation. 
Acknowledgments

The authors would like to thank the editor of IJSS for their valuable time, support and advice in completing the current study.

\section{References}

Akbari, R., Behzadpoor, F., \& Dadvand, B. (2010). Development of English language teaching reflection inventory. System, 38(2), 211-227. https://doi.org/10.1016/j.system.2010.03.003

Astawa, I. N., Mantra, I. B. N., \& Widiastuti, I. A. M. S. (2017). Pengembangan tes bahasa inggris komunikatif untuk smk pariwisata di bali. Jurnal Bakti Saraswati (JBS): Media Publikasi Penelitian dan Penerapan Ipteks, 6(2), 140-149.

Hadjerrouit, S. (2015). Exploring the effect of teaching methods on students' learning of school informatics. In Proceedings of Informing Science \& IT Education Conference (InSITE) (Vol. 201, p. 219).

Hsieh, S. W., Jang, Y. R., Hwang, G. J., \& Chen, N. S. (2011). Effects of teaching and learning styles on students' reflection levels for ubiquitous learning. Computers \& Education, 57(1), $1194-1201$. https://doi.org/10.1016/j.compedu.2011.01.004

Keefe, J. W. (1987). Learning Style Theory and Practice. National Association of Secondary School Principals, 1904 Association Dr., Reston, VA 22091.

Killian, M., \& Bastas, H. (2015). The effects of an active learning strategy on students' attitudes and students' performances in introductory sociology classes. Journal of the Scholarship of Teaching and Learning, 15(3), 5367.

Kumaravadivelu, B. (1993). Maximizing learning potential in the communicative classroom. ELT journal, 47(1), 1221. https://doi.org/10.1093/elt/47.1.12

Kumaravadivelu, B. (2006). TESOL methods: Changing tracks, challenging trends. Tesol Quarterly, 40(1), 59-81. https://doi.org/10.2307/40264511

Moussa-Inaty, J., Atallah, F., \& Causapin, M. (2019). Instructional Mode: A Better Predictor of Performance Than Student Preferred Learning Styles. International Journal of Instruction, 12(3), 17-34. https://doi.org/10.29333/iji.2019.1232a

Salam, M., Ibrahim, N., \& Sukardjo, M. (2019). Effects of Instructional Models and Spatial Intelligence on the Mathematics Learning Outcomes after Controlling for Students' Initial Competency. International Journal of Instruction, 12(3), 699-716. https://doi.org/10.29333/iji.2019.12342a

Widiastuti, I. A. M. S. (2018). Teachers' classroom assessment and grading practices. In SHS Web of Conferences (Vol. 42, p. 00052). EDP Sciences.

Widiastuti, I. A. M. S., \& Md, I. A. (2017). Teachers' Understanding of Formative Assessment. Jurnal Bahasa dan Seni, 45(1), 50-63.

Widiastuti, I. A. M. S., \& Saukah, A. (2017). Formative assessment in efl classroom practices. Bahasa dan Seni: Jurnal Bahasa, Sastra, Seni, dan Pengajarannya, 45(1), 50 . http://journal2.um.ac.id/index.php/jbs/article/view/677/419

Yusuf, Q., Jusoh, Z., \& Yusuf, Y. Q. (2019). Cooperative Learning Strategies to Enhance Writing Skills among Second Language Learners. International Journal of Instruction, 12(1), 1399-1412. https://doi.org/10.29333/iji.2019.12189a 